\title{
A Comparative Study of Clustering Protocols for Wireless Sensor Network
}

\author{
Navpreet Kaur \\ Student of M. Tech C.S.E \\ 194 Akash Avenue \\ F.C Road Amritsar
}

\begin{abstract}
Power and bandwidth of the receptors are appreciated assets and necessary to consume proficiently in the approval based WSNs condition. Flooding is caused by details collecting or amassing by individual nodes which cause highest possible energy utilization. Hence, to overcome with this issue a new details collecting or amassing strategy can be suggested to increase the performance of the heterogeneous WSNs using the team based details collecting or amassing. In this document, the current research on the clustering and details collecting or amassing based methods has been explored. Moreover document discusses various restrictions in the earlier methods in the tabular type.
\end{abstract}

\section{General Terms}

Clustering, limited battery, energy efficient.

\section{Keywords}

WSN- wireless sensor network, LEACH-Low energy adaptive clustering hierarchy, DEEC-Distributed Energy Effective Clustering, EECS-Energy efficient clustering scheme, DDEECDeveloped Distributed Energy Effective Clustering.

\section{INTRODUCTION}

Wireless Indicator system composes of many small allocated various sensor nodes that provide the efficient monitoring in various different environments such as military and civil programs. In WSN every sensor node contains particular components receiving components, memory, processing unit, which are required. With the help of social media tiny sensor nodes, it becomes easy to acquire the details about physical phenomena which was quite difficult with fliers and business cards. These node procedure details and deliver it to platform place known as sink node or the target node. For interaction of details between nodes and sink node many redirecting technological innovation are used initially, such as immediate interaction and multiple hop details transmitting. But due to limited battery of nodes these methods were not so effective because of early death of some nodes in both methods were fail to get the system suitability periods.

\section{CLUSTERING TECHNIQUE}

In clustering various sensor nodes are grouped by means of groups. In each and every team there is a cluster head which acts as a leader of the team. All nodes which belongs to that particular team have to deliver their particular details to the cluster head of that particular team and then cluster head is responsible for aggregating the details and sends that aggregated details to platform place straight. Only cluster head have the capability to perform immediate interaction with platform place. Clustering is useful for Useful energy intake and it also declines the interaction expense for both single and multi-hop techniques.

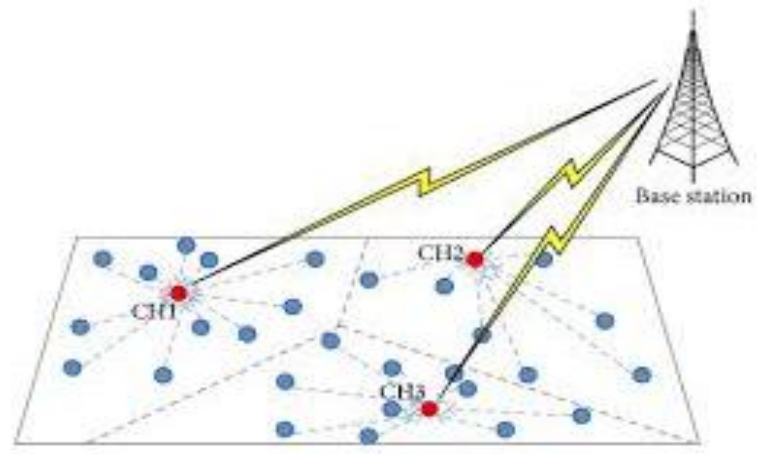

Figure 1.2: Clustering architecture [2]

\subsection{LEACH (Low Energy Adaptive Clustering Hierarchy)}

LEACH [2] is just a allocated criteria for clustering. In this strategy, various sensor nodes deliver their details for their particular team leads, and then your team leads aggregates the details and then compress the details and transmits the aggregated details to the mattresses platform place. Only cluster head is responsible for straight communicating with platform place.

In this method, cluster head option is mainly based mostly on the exact range of the node and the cluster head. The node which can be closest to platform place is chosen because the "cluster head and rdquo. Nodes which are not selected as cluster head can only communicate with the cluster head in a TDMA style, according to the schedule which can be created by the cluster head. They do so by making use of the minimum energy which must reach the cluster head. Each node individually has the proper to take decision what node is usually to be chosen as "cluster head" for a particular team. This method is useful for reducing the expense and also used to reduce the energy.

\subsection{EECS (Energy Effective Clustering Scheme)}

EECS [4] strategy is same to that particular of LEACH-like clustering method, in this the system is separated into various number of groups and there's one cluster head in each and every cluster. Communication that takes between the cluster head and platform place is immediate. In this nodes are responsible for broadcasting the information for their particular neighboring nodes and the node which has highest possible recurring energy is chosen as a cluster head. This method increases plenty of duration of the system and also increases the submission of energy on the record of system. 


\subsection{DEEC (Distributed Energy Effective Clustering)}

In DEEC [4], the cluster-heads are elected on the reasons for probability in accordance with the rate between recurring energy of each node and the common energy of the complete system. The nodes which have high preliminary and recurring energy will have more chances to be chosen as cluster-heads as opposed to nodes with low energy.

\subsection{DDEEC (Developed Distributed Energy Effective Clustering)}

Developed Distributed Energy Effective Clustering strategy is focused on dynamic and efficient strategy for the option of cluster head .This strategy intensify the duration of system and also levels out the cluster head option on the reasons for particular recurring energy and preliminary energy of nodes. It also estimates the perfect value of system which can be useful for calculations of energy such as been used already. In this each and every node elects itself as a cluster head on the reasons for preliminary and recurring energy at every option circular. This strategy was useful for powerful controlling of energy similarly on the record of nodes in the system. In this, each and every sensor node individually chooses itself as a cluster head on the reasons for preliminary energy and recurring energy .This method also enhance the system life-time.

\section{LITERATURE SURVEY}

Chen, Jing, and Fengqi Yu [1] designed a brand new allocated flexible team framework redirecting method for the techniques. This redirecting strategy is allocated in nature and the option of cluster head was only influenced by the believed of energy submission among the nodes in the system. The Working of the method was split into three primary phases. First stage is known as "cluster construction", cluster construction is the team development procedure, the leads of team are chosen and then non-cluster head nodes be a part of their particular team in respect to the range and then continues to second stage that has been to the construct of cluster head shrub. Tree designed is based on the bodyweight. Cluster head that has the most bodyweight has the capability to end up being the parent node of the shrub. Lastly, team has to deliver their details for their team at once the reasons for the allocated time port and then cluster head collects details and then sends that collected details to Base place straight. This method triumphs over all of the disadvantages of LEACH and LEACH-C method. Kandasamy, Thirumal, and Jaya Kumar Krishnan [2] used a multipath nonredundant details dissemination strategy for the concern based redirecting plan to help optimize use of energy in wireless sensor system. Continuous growth in the wireless sensor system (WSN) needs redirecting method that may cater for electrical energy as in evaluation to conventionally used non-renewable resources of energy in sensor nodes. APPOLO criteria is employed to periodically and locally determine the topological knowledge range of each solar-powered node, predicated on an approximated energy price range for the following interval. Energy price range is containing the current energy, the predicted energy intake and the energy expected from the solar power panel. PISA is really a QoS conscious redirecting used for path option predicated on objective. Priority based redirecting in solar power operated wireless sensor system is applied using APOLLO and PISA. Thus energy preserving is attained for realtime path discovery. Chamam, Ali, and Samuel Pierre [3] evaluated allocated energy efficient team development method for WSN's. This method elects the cluster head by using three way method as exchanges strategy. This three way method hence increase the life-time of system. Moreover it regarded the believed of recurring energy for cluster head procedure. The Three primary information exchanged between nodes were: Score Marketing Broadcast (SAB) which reveals the capacity of a particular node to behave as a cluster head., Relative Cluster Head Rank Marketing (RCRA) which reveals this position of chosen cluster head and the Election Message which can be used to declare finally that which cluster head is likely to be in interaction with the Base Station.

Andrei Gagarin et al. [4] suggested a fresh heuristic remedy to locate a level healthy and small bodyweight redirecting comprising tress in a system. This strategy is innovative kind of kruskal's comprising shrub look for criteria and it is in regards to the concept of allocated look for by framework of various groups. It's perfect for usage of energy in redirecting in wireless sensor techniques. It produces comprising plants with a reduced highest possible calculated level, and can be utilized for healthy energy intake.

Elbhiri, Rachid et al. [5] designed Distributed Energy Effective Clustering strategy to be used in heterogeneous wireless sensor techniques. This concept is based on dynamic and efficient manner of selection of cluster head .This strategy increases the life-time of system and also levels out the cluster head option in regards to the particular recurring energy and preliminary energy. Furthermore, it determines in advance the best value of system which is used for calculations of energy which had expended. In this each and every node chooses itself as a cluster head on the foundation of preliminary and recurring energy at every option circular. This strategy was used for the concept of powerful controlling of energy similarly among the many nodes in the system.

Huang, $\mathrm{Ru}$ et al. [6] provided a Predication method based Routing Algorithm based on ACO (PRACO) to get the energyaware data-gathering redirecting framework in wireless sensor techniques (WSN). They adopted series style ARMA to analyze dynamic tendency in details traffic and deduce the development of load factor, which can help to reveal the long run energy position of sensor in WSN. By making the check of the load factor in heuristic aspect and guided by novel pheromone updating rule, artificial ants can foresee the neighborhood energy condition of techniques and the corresponding actions could possibly be adaptively taken fully to boost the energy-efficiency in redirecting development. The simulator outcomes display that the suggested redirecting building plan can effectively reinforce the robustness of redirecting framework by mining the temporal associability and introducing ACO to balance the complete energy cost for details transmitting, which also contributes to reduce the complete interaction intake, meanwhile, to prolong the life-time of networks.

Dong, Yuping et al. [7]proposed a redirecting criteria which separates the sensor nodes a variety of scheduling sets and monitors the level of energy of each sensor. This criteria levels out energy intake among receptors, and therefore extends the system life-time. Simulation outcomes verify that criteria outperforms the EECCR criteria suggested in.

Vinh, Thuy Tran et al. [8] suggested a multipath remedy for event-driven cluster-based redirecting in WSN known as Energy-Aware MeshRouting Protocol (EMRP) with primary style features: straight answers transmitting, fill balance and energy-efficiency. Furthermore, using the rest of the energy as primary parameter for dynamically switching between two 
alternative paths, EMRP could be also applied for purpose of the virtualization of wireless sensor network. Hence the simulator outcomes display that our remedy accomplishes better performance than other event-driven cluster-based redirecting protocols.

Beheshtiha et al. [9] designed OR-AHaD, an Opportunistic Routing criteria with Adaptive Harvesting-aware Responsibility Riding a bike. In the suggested criteria, candidates are primarily prioritized through the use of geographical zoning and later coordinated in a timer-based style by exchanging coordination information. An energy management style is provided that uses the approximated growing amount in the long run to adjust the work cycle of each node adaptively. Simulation outcomes display that OR-AHaD exploits the available energy resources in a powerful way and increases good put in evaluation to other opportunistic redirecting protocols for WSN-HEAP.

Hady S. Abdel Salam et al. [10] suggested various methods in the literature to handle some of the basic issues faced by an indicator system style. All of the suggested methods tries to solve one issue in separation from another issues. Hence, method designers had to face those common difficulties again and again. This, indirectly, functions a immediate influence on the complexness of the protocols and on energy use of protocols. Instead of using that strategy, he suggested BEES, a light development method, that makes it possible to reduce many of the common difficulties in sensor techniques by allowing the development of simpler system protocols. He proven that how BEES can help reduce plenty of the common difficulties relevant to sensor techniques including localization of receptors, clustering of details and details collecting or amassing. Kim, Jaekwang, and Jee-Hyong Lee [11] suggested ViTAMin (Virtual backbone Tree Algorithm), a Exclusive central source Tree Algorithm for Little energy intake in WSN redirecting. ViTAMin provides more energy-efficient redirecting than do EVBT and MCBT, as a result of efficient selecting of upstream link. Although the simulator experiments, ViTAMin performed well with minimal energy intake and a sufficient system life-time in WSN redirecting. Ren,Chen et al. [12] introduced a powerful band based multi-hop team redirecting method for WSN's. This method was primary concerned on the rest of the energy and also cluster head variety for the option of cluster head. It has multi-round clustering technique. In this each and every node select itself as a cluster head by considering the length aspect. After the option of cluster head, cluster head has to deliver notification to all or any other nodes in the system to see them that in that particular band that node has transformed into the cluster head .The other nodes have to become listed on the cluster head on the foundation of range between them. Distance aspect was mainly designed to truly save the energy. In this, nodes are allotted their particular time spots .This method triumphs over the disadvantage of band based multi-hop clustering.

Pratyay Kuila Prasanta K. Jana [13] stated that Clustering sensor nodes is an excellent strategy which increases scalability and lifetime of a radio sensor system (WSN). In a selection based WSN, the leaders (cluster heads) takes in huge amount of energy due with a extra fill for various activities such as assortment of details, collecting or amassing of details, and the interaction of the aggregated details to the platform place. Thus, the controlling force of the team leads is a major issue for the long run operation of the WSNs. He first provided some fill controlling clustering schemes for wireless sensor techniques. He proven that the criteria runs in $\mathrm{O}(\mathrm{n} \log n)$ here we are at $\mathrm{n}$ sensor nodes and that criteria is better for the case in that your sensor nodes have equivalent fill.

Dang, Nga et al. [14] suggested to continuously adapt the energy requirements of sensor nodes depending on availability of electrical energy, system redirecting needs and program high quality constraints - addressing these trade-offs is distinctive contribution. They provided a novel criteria to find the optimal uniform details high quality for approximated details selection in a multi-hop energy-harvesting wireless sensor system (EHWSN). Their strategy guarantees redirecting sustainability in the system and has a lesser amount of failed details queries $(<; 2 \%)$ as in evaluation to a state-of-the-art energy-harvesting-aware redirecting method which can be not conscious of details high quality.

Ganesh et al. [15] modified the ad-hoc on demand range vector redirecting by incorporating signal-to-noise rate (SNR) based powerful clustering. The suggested plan, which can be a powerful and protected redirecting method for wireless sensor techniques through SNR-based powerful clustering (ESRPSDC) techniques, can partition the nodes into groups and find the cluster head $(\mathrm{CH})$ among the nodes in accordance with the energy, and non $\mathrm{CH}$ nodes be a part of with a particular $\mathrm{CH}$ on the reasons for the SNR values. Mistake restoration has been applied during the inter-cluster redirecting to be able to avoid end-to-end error restoration. Protection has been achieved by isolating the malicious nodes using sink-based redirecting pattern analysis. Extensive investigation studies employing a international cellular simulator display that hybrid ESRP considerably increases the energy-efficiency and bundle wedding celebration amount as weighed against the SNR unaware redirecting methods like the low energy conscious flexible clustering framework and energy efficient collecting in sensor computer.

Hong, Zhang et al. [16] suggested a powerful and powerful team plan method for heterogeneous multilevel Wi-fi sensor system.This method focuses only on the cluster head procedure. In this, team leads are chosen on the foundation of energy which they have in a certain circular and therefore, it depends upon the energy which the node takes in in each circular. In this all nodes are allocated a person port time, and in those days particular node conveys with cluster head and depending on allocated spots interaction procedure continues and then cluster head is responsible for contracting all the details that was received by nodes and then after contracting cluster head conveys with the mattresses platform place straight .This method is used to get rid of the restrictions of LEACH, SEP, DEEC protocols.

Khan, Y. et al. [17] suggested new clustering methods in redirecting protocols, Location-aware Long lasting $\mathrm{CH}(\mathrm{LPCH})$ and User Defined Location-aware Long lasting CH (UDLPCH). In both protocols, system field is physically divided in to two regions, equivalent variety of nodes are randomly applied in each area. In $\mathrm{LPCH}$, variety of $\mathrm{CHs}$ are chosen by $\mathrm{LEACH}$ criteria in first circular. Yet in UDLPCH, equivalent and optimum variety of $\mathrm{CHs}$ are chosen in each area, through the whole system whole lifestyle variety of $\mathrm{CHs}$ are remain same. Simulation outcomes display that balance interval and throughput of $\mathrm{LPCH}$ is greater than $\mathrm{LEACH}$, balance interval and throughput of UDLPCH is greater than LPCH. Amgoth, Tarachand, and Prasanta K. Jana [18] suggested a energy conscious redirecting criteria for team based WSNs. The criteria is depending on a brilliant strategy of cluster head $(\mathrm{CH})$ option, recurring energy of the $\mathrm{CHs}$ and the intra-cluster range for team development. To facilitate details redirecting, a directed virtual 
central source of $\mathrm{CHs}$ is designed that is rooted at the drain. The suggested criteria can be proven to balance energy intake of the $\mathrm{CHs}$ during details redirecting procedure. They proven that the criteria accomplishes constant concept and straight line time complexness. They tested the suggested criteria extensively. The experimental outcomes display that the criteria outperforms other current methods in terms of system life-time, energy intake and other parameters.

\section{COMPARISON TABLE}

Table 1 is showing comparison among the available protocols used in wireless sensor network. It has already shown that no protocol is perfect. Each protocol has its own benefits over others but still it suffers from certain limitations.

Table 1 Reveals the Evaluation of the Various Methods.

\begin{tabular}{|c|c|c|c|c|c|}
\hline Ref. & Authors & Year & Technique & Features & Limitations \\
\hline [1] & $\begin{array}{l}\text { Chen, Jing, and } \\
\text { Fengqi Yu }\end{array}$ & 2007 & $\begin{array}{l}\text { distributed adaptive cluster hierarchy } \\
\text { routing protocol }\end{array}$ & $\begin{array}{l}\text { overcomes all of the } \\
\text { drawbacks of LEACH and } \\
\text { LEACH-C protocol }\end{array}$ & $\begin{array}{l}\text { The effects of the mobile } \\
\text { sink has been ignored. }\end{array}$ \\
\hline [2] & $\begin{array}{l}\text { Kandasamy, } \\
\text { Thirumal, and } \\
\text { Jaya Kumar } \\
\text { Krishnan }\end{array}$ & 2008 & $\begin{array}{l}\text { priority based routing scheme } \\
\text { APPOLO algorithm }\end{array}$ & energy saving & $\begin{array}{l}\text { The effect of lossless } \\
\text { data compression has } \\
\text { been neglected }\end{array}$ \\
\hline [3] & $\begin{array}{l}\text { Chamam, Ali, } \\
\text { and } \\
\text { Pierre }\end{array}$ & 2009 & $\begin{array}{l}\text { distributed energy efficient cluster } \\
\text { formation protocol }\end{array}$ & $\begin{array}{l}\text { enhances the lifetime of } \\
\text { network }\end{array}$ & $\begin{array}{l}\text { No optimization } \\
\text { technique is considered }\end{array}$ \\
\hline [4] & $\begin{array}{l}\text { Gagarin Andrei, } \\
\text { HussainSajid, } \\
\text { Laurence, Yang } \\
\text { T }\end{array}$ & 2010 & $\begin{array}{l}\text { kruskal's spanning } \\
\text { algorithm and }\end{array}$ & $\begin{array}{l}\text { generates spanning trees } \\
\text { with a diminished } \\
\text { maximum weighted degree }\end{array}$ & $\begin{array}{l}\text { The effects of the mobile } \\
\text { sink has been ignored. }\end{array}$ \\
\hline [5] & $\begin{array}{l}\text { Elbhiri, Rachid, } \\
\text { and fkihi }\end{array}$ & 2010 & $\begin{array}{l}\text { Distributed Energy } \\
\text { Clustering technique }\end{array}$ & $\begin{array}{l}\text { improves the lifetime of } \\
\text { network }\end{array}$ & $\begin{array}{l}\text { The effect of lossless } \\
\text { data compression has } \\
\text { been neglected }\end{array}$ \\
\hline [6] & $\begin{array}{l}\text { Huang, } \mathrm{Ru}, \\
\text { Zhihua Chen, and } \\
\text { Guanghui } \mathrm{Xu}\end{array}$ & 2010 & $\begin{array}{l}\text { Predication mode } \\
\text { based Routing Algorithm centered on } \\
\text { ACO }\end{array}$ & $\begin{array}{l}\text { balance } \\
\text { total energy cost for data } \\
\text { transmission }\end{array}$ & $\begin{array}{l}\text { No optimization } \\
\text { technique is considered }\end{array}$ \\
\hline [7] & $\begin{array}{l}\text { Dong, Yuping, } \\
\text { Hwa Chang, } \\
\text { Zhongjian Zou, } \\
\text { and Sai Tang. }\end{array}$ & 2010 & routing algorithm & $\begin{array}{l}\text { prolongs the network } \\
\text { lifetime }\end{array}$ & $\begin{array}{l}\text { The effects of the mobile } \\
\text { sink has been ignored. }\end{array}$ \\
\hline [8] & $\begin{array}{l}\text { Vinh, Thuy Tran, } \\
\text { Thu Ngo Quynh, } \\
\text { and Mai Banh } \\
\text { Thi Quynh }\end{array}$ & 2012 & $\begin{array}{l}\text { multipath solution for event-driven } \\
\text { cluster-based routing }\end{array}$ & $\begin{array}{l}\text { reliable data transmission, } \\
\text { load balance and } \\
\text { energy efficiency }\end{array}$ & $\begin{array}{l}\text { The effect of lossless } \\
\text { data compression has } \\
\text { been neglected }\end{array}$ \\
\hline [9] & \begin{tabular}{l}
\multicolumn{2}{l}{ Beheshtiha, } \\
Sanam Shirazi, \\
Hwee-Pink Tan, \\
and Masoud \\
Sabaei
\end{tabular} & 2012 & $\begin{array}{l}\text { Opportunistic Routing algorithm } \\
\text { with Adaptive Harvesting- } \\
\text { aware Duty Cycling }\end{array}$ & $\begin{array}{l}\text { uses the estimated } \\
\text { harvesting rate }\end{array}$ & $\begin{array}{l}\text { No optimization } \\
\text { technique is considered }\end{array}$ \\
\hline [10] & $\begin{array}{l}\text { Abdel salam HS, } \\
\text { Olariu S. }\end{array}$ & 2012 & BEES & $\begin{array}{l}\text { mitigate lots of the typical } \\
\text { challenges related to sensor } \\
\text { networks }\end{array}$ & $\begin{array}{l}\text { The effects of the mobile } \\
\text { sink has been ignored. }\end{array}$ \\
\hline [11] & $\begin{array}{ll}\text { Kim, Jaekwang, } \\
\text { and Jee-Hyong } \\
\text { Lee }\end{array}$ & 2012 & $\begin{array}{l}\text { Virtual backbone Tree Algorithm for } \\
\text { Minimal }\end{array}$ & energy-efficient routing & $\begin{array}{l}\text { The effect of lossless } \\
\text { data compression has } \\
\text { been neglected }\end{array}$ \\
\hline$[12]$ & $\begin{array}{l}\text { Ren F, Zhang J, } \\
\text { He T, Lin C, Das } \\
\text { SK. }\end{array}$ & 2011 & multi-hop cluster routing protocol & $\begin{array}{l}\text { overcomes the drawback of } \\
\text { ring based multi-hop } \\
\text { clustering }\end{array}$ & $\begin{array}{l}\text { No optimization } \\
\text { technique is considered }\end{array}$ \\
\hline$[15]$ & $\begin{array}{l}\text { Ganesh, } \\
\text { Subramanian, } \\
\text { and } \\
\text { Ramachandran } \\
\text { Amutha. }\end{array}$ & 2013 & $\begin{array}{lcc}\text { SNR-based } & \text { dynamic } & \text { clustering } \\
\text { (ESRPSDC) mechanisms } & \end{array}$ & $\begin{array}{l}\text { improves } \\
\text { the energy efficiency and } \\
\text { packet reception rate }\end{array}$ & $\begin{array}{l}\text { The effects of the mobile } \\
\text { sink has been ignored. }\end{array}$ \\
\hline$[16]$ & $\begin{array}{l}\text { HONG, Zhen, Li } \\
\text { YU, and Gui-Jun } \\
\text { ZHANG }\end{array}$ & 2013 & dynamic cluster scheme protocol & $\begin{array}{l}\text { get rid of the limitations of } \\
\text { LEACH, SEP, DEEC } \\
\text { protocols }\end{array}$ & $\begin{array}{l}\text { The effect of lossless } \\
\text { data compression has } \\
\text { been neglected }\end{array}$ \\
\hline [17] & $\begin{array}{l}\text { Khan, } \quad \text { Y., } \\
\text { Nadeem Javaid, } \\
\text { M. J. Khan, Y. }\end{array}$ & 2013 & UDLPCH & $\begin{array}{l}\text { stability period and } \\
\text { throughput of UDLPCH is } \\
\text { higher than LPCH }\end{array}$ & $\begin{array}{l}\text { No optimization } \\
\text { technique is considered }\end{array}$ \\
\hline
\end{tabular}




\begin{tabular}{|l|l|l|l|l|l|}
\hline & $\begin{array}{l}\text { Ahmad, M. H. } \\
\text { Zubair, and S. A. } \\
\text { Shah. }\end{array}$ & & & \\
\hline$[18]$ & $\begin{array}{l}\text { Amgoth, } \\
\text { Tarachand, and } \\
\text { Prasanta K. Jana }\end{array}$ & 2014 & Energy-aware routing algorithm & $\begin{array}{l}\text { achieves constant message } \\
\text { and linear time complexity }\end{array}$ & $\begin{array}{l}\text { The effects of the mobile } \\
\text { sink has been ignored. }\end{array}$ \\
\hline
\end{tabular}

\section{CONCLUSION AND FUTURE WORK}

In this document, the review has proven that the most of the current methods has ignored the use of the consequences of the cellular drain in the most of the energy efficient protocols has been ignored. Moreover the impact of lossless details pressure has also been ignored by the most of the researchers.

So in order to remove these issues a new approaches will be suggested using the Ant colony marketing based marketing strategy for energy efficient redirecting criteria in future.

\section{REFERENCES}

[1] Chen, Jing, and Fengqi Yu. "A uniformly allocated flexible clustering framework redirecting method."InIntegration Technological innovation, 2007.ICIT'07. IEEE Worldwide Meeting on, pp. 628-632. IEEE, 2007.

[2] Kandasamy, Thirumal, and Jaya Kumar Krishnan. "Using multipath concern redirecting for solar power operated wireless sensor techniques." In Information Technological innovation, 2008. ITSim 2008. Worldwide Symposium on, vol. 4, pp. 1-6. IEEE, 2008.

[3] Chamam, Ali, and Samuel Pierre. "A allocated energyefficient team development method for wireless sensor techniques."InConsumer Emails and Networking Meeting, 2009.CCNC 2009. 6th IEEE, pp. 1-5. IEEE, 2009

[4] Gagarin Andrei, HussainSajid, Laurence, T. Distributed hierarchical look for for healthy energy intake redirecting comprising plants in wireless sensor techniques. J Similar DistribComput 2010;70:975-82

[5] Elbhiri, Rachid , and fkihi"Developed Distributed Energy Effective Clustering for heterogeneous wireless sensor techniques."Wireless Emails and Networking, 2010WCNC 2010.2010 IEEE.Vol. 2.IEEE, 2010

[6] Huang, Ru, Zhihua Chen, and Guanghui Xu. "Energy-aware Routing Algorithm in WSN using Predication-mode." In Emails, Circuits and Systems (ICCCAS), 2010 Worldwide Meeting on, pp. 103-107. IEEE, 2010.

[7] Dong, Yuping, Hwa Alter, Zhongjian Zou, and Sai Tang. "Energy conscious redirecting criteria for WSN programs in border surveillance." In Technologies for Homeland Protection (HST), 2010 IEEE Worldwide Meeting on, pp. 530-535. IEEE, 2010.

[8] Vinh, Thuy Tran, Thu Ngo Quynh, and Mai Banh Thi Quynh. "EMRP: energy-aware mesh redirecting method for wireless sensor techniques." In Advanced Technologies for Emails (ATC), 2012 Worldwide Meeting on, pp. 78-82. IEEE, 2012.
[9] Beheshtiha, Sanam Shirazi, Hwee-Pink Tan, and Masoud Sabaei. "Opportunistic redirecting with Adaptive Harvesting-aware Responsibility Riding a bike in energy growing WSN." In Wi-fi Personal Multimedia Emails (WPMC), 2012 15th Worldwide Symposium on, pp. 90-94. IEEE, 2012.

[10] Abdel salam HS, Olariu S. BEES: BioinspirEdBackbonE Selection in wireless sensor techniques. IEEE Trans Similar DistribSyst 2012;23:44-51.

[11] Kim, Jaekwang, and Jee-Hyong Lee. "ViTAMin: A Exclusive Backbone Tree Algorithm for Little energy intake in wireless sensor system redirecting." In Information Networking (ICOIN), 2012 Worldwide Meeting on, pp. 144-149. IEEE, 2012.

[12] Ren F, Zhang J, He T, Lin C, Das SK. EBRA: energybalanced redirecting method for details collecting in wireless sensor techniques. IEEE Trans Similar DistribSyst 2011;22:2018-125.

[13] Kuila P, Gupta SK, Jana Prasanta K. A novel evolutionary strategy for fill healthy clustering issue for wireless sensor techniques. Swarm Evol Comput 2013;12:48-56.

[14] Dang, Nga, Mahnaz Roshanaei, Eli Bozorgzadeh, and Nalini Venkatasubramanian. "Adapting details high quality with multihop redirecting for energy growing wireless sensor techniques." In Green Processing Meeting (IGCC), 2013 Worldwide, pp. 1-6. IEEE, 2013.

[15] Ganesh, Subramanian, and Ramachandran Amutha. "Efficient and protected redirecting method for wireless sensor techniques through SNR based powerful clustering techniques." Emails and Networks, Journal of 15, no. 4 (2013): 422-429.

[16] HONG, Zhen, Li YU, and Gui-Jun ZHANG. "Efficient and powerful clustering plan for heterogeneous multi-level wireless sensor techniques." Acta Automatica Sinica 39, no. 4 (2013): 454-460.

[17] Khan, Y., Nadeem Javaid, M. J. Khan, Y. Ahmad, M. H. Zubair, and S. A. Shah. "LPCH and UDLPCH: Locationaware Routing Associated with WSNs." InBroadband and Wi-fi Processing, Communication and Applications (BWCCA), 2013 Eighth Worldwide Meeting on, pp. 100105. IEEE, 2013.

[18] Amgoth, Tarachand, and Prasanta K. Jana. "Energy-aware redirecting criteria for wireless sensor techniques." Computers \& Electrical Engineering (2014). 